AFTER LIFE 



\section{AFTER LIFE}

an ethnographic novel

\section{TOBIAS HECHT}

with portions based

on the narrations

of Bruna Veríssimo

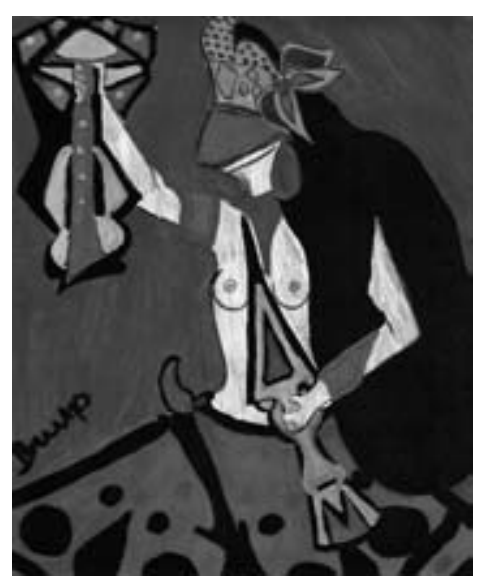

Duke University Press Durham and London 2006 


\section{(c) 2006 Duke University Press}

All rights reserved

Printed in the United States of

America on acid-free paper @

Designed by C. H. Westmoreland

Typeset in Scala by Tseng Information

Systems, Inc.

Misproject display font by Eduardo Recife

(www.misprintedtype.com)

Library of Congress Cataloging-in-

Publication Data appear on the last

printed page of this book.

Acknowledgments and illustration

credits follow the text of the novel. 
for my father 
